\title{
Produtos Poliolefínicos Reciclados com Desempenho Superior aos Materiais Virgens Correspondentes
}

\author{
Agnes F. Martins, João Carlos M. Suarez e Eloisa B. Mano
}

\begin{abstract}
Resumo: O balanço das reações de reticulação e cisão em cadeias poliolefínicas, quando expostas a condições ambientais de radicais livres, pode resultar em boas propriedades e novas aplicações. Materiais descartados de alta qualidade despertam cada vez mais interesse para reciclagem. Os resíduos plásticos de embalagens alimentícias, assim como peças descartadas de grandes dimensões, provenientes da indústria automotiva, são exemplos daqueles materiais. No presente trabalho, são relatadas as propriedades mecânicas da madeira plástica IMAWOOD, obtida a partir de resíduos sólidos urbanos, principalmente embalagens de polietileno, e do material IMACAR, recuperado de pára-choques descartados de carros de passeio, constituído basicamente de misturas PP/EPDM. Verificou-se que o IMAWOOD mostrou comportamento mecânico melhorado por efeito da radiação-gama, enquanto que o IMACAR revelou alta resistência ao impacto, muito superior ao material virgem de composição correspondente.
\end{abstract}

Palavras-chave: Plástico reciclado, plástico recuperado, mistura de polietilenos, radiação-gama, propriedades mecânicas, pára-choques de carros.

\section{Introdução}

O desenvolvimento de pesquisas sobre plástico reciclado tem permitido detectar características de inovação bastante surpreendentes, associadas às vantagens bem conhecidas da recuperação do material reciclado. O IMA tem se destacado neste particular, uma vez que os estudos realizados com os produtos reciclados procuram analisar os resultados, comparando-os ao desempenho de materiais de composição semelhante, no estado virgem. São consideradas as modificações sofridas pelos materiais pós-consumidos e relegados a condições incontroláveis de agressão ambiental.

A exposição de polímeros às radiações ionizantes altera a sua estrutura molecular e as suas propriedades $^{[1,2]}$. Ocorre a formação de ligações cruzadas entre as cadeias, paralelamente à cisão entre átomos. A reticulação provoca um aumento do peso molecular, que geralmente ocasiona a melhoria das propriedades, enquanto que a cisão das cadeias reduz o seu peso, tendo como resultado final a deterioração das propriedades. Como o polietileno após irradiação apresenta reticulação, pode-se esperar uma melhoria nas suas propriedades mecânicas. Em conseqüência, as misturas de polietilenos reciclados, quando irradiadas, devem também apresentar boas propriedades, permitindo encontrar novas aplicações para esses materiais.

O problema da poluição ambiental é cada vez mais preocupante, especialmente em relação aos resíduos produzidos por indústrias de grande porte, 
como a indústria automobilística. Os pára-choques de carros de passeio, que são produtos de alta qualidade técnica e grandes dimensões, têm sido muito visados para fins de reciclagem. Esse procedimento reduz os custos de matéria-prima, o que diminui o consumo total de energia na manufatura do produto, e reduz os problemas ambientais, no que diz respeito ao descarte de materiais usados ${ }^{[3-6]}$.

Altos níveis de rigidez e resistência mecânica, ao lado de grande resistência ao impacto, são qualidades conflitantes, embora muito importantes para o desenvolvimento satisfatório de pára-choques de carros de passeio. Para alcançar o balanço adequado dessas propriedades, a indústria automotiva lança mão de misturas poliméricas, considerando sempre a relação custo-benefício. A adição de elastômeros a termoplásticos aumenta a resistência ao impacto sem grande prejuízo da rigidez, resistência mecânica, estabilidade térmica e processabilidade, preservando assim no material um conjunto de propriedades desejáveis ${ }^{[7]}$.

No presente trabalho, são abordadas as características mecânicas em dois tipos de materiais poliolefínicos distintos, IMAWOOD ${ }^{\circledR}$ e IMACAR ${ }^{\circledR}$, cujas marcas já foram registradas pelo IMA. O IMAWOOD $^{\circledR}$, madeira plástica, provém de material pós-consumido (sacos e sacolas plásticas), recuperado dos depósitos de lixo da COMLURB, após tratamento segundo tecnologia desenvolvida no IMA; consiste basicamente de mistura LDPE/ HDPE 3:1. O IMACAR ${ }^{\circledR}$ resulta de material recuperado de pára-choques descartados de carros de passeio, obtidos de "ferros-velhos" dos subúrbios da cidade do Rio de Janeiro. De modo geral, consiste de mistura de poliolefinas, com predominância de PP e baixo teor de EPDM. O IMAWOOD ${ }^{\circledR}$, quando exposto a baixas doses de radiação-gama apresentou melhoria no seu desempenho mecânico, especialmente resistência à compressão e tração. O IMACAR ${ }^{\circledR}$ mostrou ser altamente resistente ao impacto, superior ao material de composição semelhante, obtido a partir de polímeros virgens.

\section{Experimental}

\section{IMAWOOD ${ }^{\circledR}$}

Para o estudo do IMAWOOD ${ }^{\circledR}$, mistura de polietilenos reciclados (cerca de $75 \%$ de polietileno de baixa densidade, LDPE, e $25 \%$ de polietileno de alta densidade, HDPE), cujo modo de obtenção foi apresentado em trabalhos anteriores ${ }^{[8,9]}$, foram selecionadas placas injetadas com $3 \mathrm{~mm}$ de espessura e barras extrusadas de seção quadrada com $20 \mathrm{~mm}$ de lado.

Os corpos de prova utilizados nos ensaios mecânicos foram fabricados por usinagem. Das placas foram obtidos os corpos de prova de tração, enquanto que os de compressão foram preparados a partir das barras extrusadas. Alguns corpos de prova permaneceram como recebidos, enquanto que os demais foram irradiados ao ar. A irradiação foi realizada em equipamento industrial, com fonte de ${ }^{60} \mathrm{Co}$; os materiais receberam doses totais de 10,500 , 1000 e $2000 \mathrm{kGy}$, à taxa de dose de $2,5 \mathrm{kGy} / \mathrm{h}$.

$\mathrm{O}$ ensaio de tração foi realizado à temperatura ambiente segundo a norma ASTM D $1708^{[10]}$, com velocidade de ensaio de $10 \mathrm{~mm} / \mathrm{min}$. O ensaio de compressão foi executado de acordo com a norma ASTM D 695(M) ${ }^{[11]}$, utilizando-se uma velocidade de $1,30 \mathrm{~mm} / \mathrm{s}$. Foram determinados o limite de resistência e o alongamento na ruptura em tração, a tensão para $50 \%$ de deformação e o limite de elasticidade por compressão.

\section{IMACAR ${ }^{\circledR}$}

Os procedimentos empregados no beneficiamento preliminar da matéria-prima in natura, na separação por densidade dos fragmentos de pára-choques, na identificação dos fragmentos predominantes e no processamento desses materiais, bem como sua discussão, estão descritos em trabalhos anteriores ${ }^{[12,13]}$. $\mathrm{O}$ ensaio de tração foi realizado à temperatura ambiente, segundo a norma ASTM D $1708^{[10]}$, com velocidade de ensaio de $10 \mathrm{~mm} / \mathrm{min}$. O ensaio de impacto Izod foi realizado segundo a norma ASTM D 256, método $\mathrm{A}^{[14]}$, nas seguintes condições: temperatura ambiente; pêndulos de 1 e 5 lbf.ft. A análise morfológica, por microscopia eletrônica de varredura, foi realizada em amostra criofraturada após imersão em nitrogênio líquido, no aumento de 7500X, com superfície de fratura recoberta de ouro.

\section{Resultados e Discussão}

\section{IMAWOOD ${ }^{\circledR}$}

Os resultados do ensaio de tração, limite de resistência e alongamento na ruptura, antes e após a irradiação das amostras, estão apresentados na Ta- 
Tabela 1. Resultados dos ensaios de tração e de compressão do IMAWOOD ${ }^{\circledR}$, antes e após irradiação ao ar

\begin{tabular}{|c|c|c|c|c|}
\hline \multirow{2}{*}{$\begin{array}{l}\text { Dose } \\
\text { (kGy) }\end{array}$} & \multicolumn{2}{|c|}{ Tração } & \multicolumn{2}{|c|}{ Compressão } \\
\hline & $\begin{array}{l}\text { Limite de } \\
\text { resistência } \\
\quad(\mathrm{MPa})\end{array}$ & $\begin{array}{c}\text { Alongamento } \\
\text { na ruptura } \\
(\%)\end{array}$ & $\begin{array}{c}\text { Limite de } \\
\text { elasticidade } \\
\text { (MPa) }\end{array}$ & $\begin{array}{c}\text { Tensão } 50 \% \\
\text { deformação } \\
\text { (MPa) }\end{array}$ \\
\hline 0 & 12,4 & 176 & 501,3 & 8,0 \\
\hline 10 & 13,2 & 197 & 498,6 & 8,8 \\
\hline 100 & 13,3 & 163 & 524,2 & 9,4 \\
\hline 500 & 13,2 & 67 & 511,3 & 9,2 \\
\hline 2000 & 14,4 & 33 & 661,4 & 9,1 \\
\hline
\end{tabular}

bela 1 e na Figura 1. O material antes da irradiação apresentou 12,4 MPa de limite de resistência, com $176 \%$ de alongamento na ruptura, mostrando alta plasticidade, com grande redução de área na região de fratura. Com a irradiação, ocorreu um pequeno aumento no limite de resistência, que se acentuou após irradiação nas doses mais elevadas. O material apresentou endurecimento por deformação (strain hardening), embora a variação do limite de resistência com a dose de radiação tenha sido relativamente pequena. Para as doses maiores, ocorreu uma sensível redução no alongamento na ruptura e, conseqüentemente, diminuição na plasticidade do material, quando comparado ao não irradiado.

Em resumo, o plástico reciclado apresenta, para a dose de $2000 \mathrm{kGy}$, um aumento de cerca de $15 \%$ no limite de resistência, com uma redução total no alongamento de aproximadamente $80 \%$. É interessante observar que, para a dose de 100 $\mathrm{kGy}$, ocorre um aumento de $10 \%$ na resistência à tração, com apenas $20 \%$ de redução no alongamento. Esses resultados indicam que o plástico

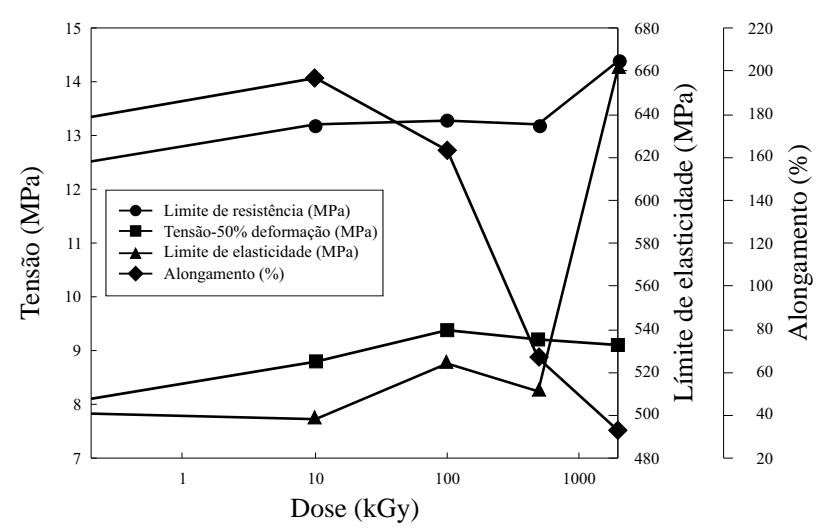

Figura 1. Resultados dos ensaios de tração e d e compressão do IMAWOOD $^{\circledR}$, antes e após irradiação ao ar reciclado apresenta uma transição dúctil-frágil em tração, com o aumento da dose de radiação. Esta transição está caracterizada pela diminuição no alongamento na ruptura (de $176 \%$ para $33 \%$ ) e ocorre entre $100 \mathrm{kGy}$ e $500 \mathrm{kGy}$.

Os resultados obtidos no ensaio de compressão constam da Tabela 1 e da Figura 1. Verifica-se que os valores da tensão para $50 \%$ de deformação cresceram, com o aumento da dose de radiação até 100 $\mathrm{kGy}$, de 8,0 MPa para 9,4 MPa. Doses mais elevadas acarretam uma tendência à estabilização na tensão. $\mathrm{O}$ valor do limite de elasticidade do material não irradiado está dentro da faixa de valores encontrada na literatura ${ }^{[15]}$; para o HDPE, este limite varia entre 350 a $700 \mathrm{MPa}$. O limite de elasticidade do material irradiado em relação ao não irradiado mostrou um aumento inferior a $5 \%$, de $498,6 \mathrm{MPa}$ a $524,2 \mathrm{MPa}$ (100 kGy). No entanto, na maior dose (2000 kGy) observou-se um aumento mais acentuado $(661,4$ $\mathrm{MPa}$ ), o que indica maior rigidez do plástico reciclado com o prolongamento do tempo de exposição, o que corrobora os resultados do ensaio de tração.

\section{IMACAR ${ }^{\circledR}$}

A caracterização tecnológica das poliolefinas virgens, em misturas binárias e ternárias e do material reciclado proveniente de pára-choques descartados se encontra na Tabela 2 .

Os valores de densidade obtidos para o material reciclado $(0,90)$, misturas binárias $\mathrm{PP} / \mathrm{EPDM}$ $(0,89-0,90)$ e ternárias PP/HDPE/EPDM $(0,91)$ foram bem próximos ao valor correspondente ao $\mathrm{PP}$ virgem $(0,91)$. Isto indica que a presença de EPDM, ou HDPE/EPDM, não influenciou a densidade do PP, dentro do erro experimental do método utilizado. Este fato já era esperado, uma vez 
que o EPDM, que é amorfo e cuja densidade é 0,86 , está presente em pequenas quantidades, e o HDPE, mesmo sendo um polímero de alta cristalinidade, com densidade 0,94 , foi incorporado em teores muito baixos, insuficientes para comprometer a alta estabilidade da organização estrutural do PP.

Quanto à resistência à tração das poliolefinas virgens pode ser observado que o PP ofereceu maior resistência do que o HDPE, e que este polímero, maior que o EPDM. No que se refere às misturas binárias PP/EPDM e ao material reciclado, é verificado o efeito do aumento do teor de EPDM na mistura com PP. Houve uma diminuição da tensão no ponto de escoamento paralelamente a um acréscimo no alongamento na ruptura das misturas estudadas. A ausência de quebra prematura das cadeias, que seria revelado pela redução significativa do alongamento na ruptura, até mesmo antes do ponto de escoamento, sugere a compatibilidade parcial dos componentes envolvidos, confirmada pela aderência apresentada pelos grânulos elastoméricos à matriz de $\mathrm{PP}$, reveladas por microscopia eletrônica de varredura, visível na Figura 2 (a), (b) e (c).

Os valores obtidos para o material reciclado foram menores do que os valores correspondentes ao PP virgem e às misturas ternárias. Estes re- sultados podem ser explicados por tratar-se de um material já submetido à degradação ambiental, de forma incontrolável, por 12-15 anos, e reprocessado diversas vezes, estando sujeito à degradação através de radiações solares, assim como efeitos mecânicos, térmicos e químicos, isolados ou simultâneos.

Em relação à resistência à tração das misturas ternárias PP/HDPE/EPDM pode ser observado que a adição de HDPE provocou uma queda muito acentuada no alongamento na ruptura para teores de HDPE de 5, 10 e $20 \%$, em peso, quando comparado às misturas binárias PP/EPDM. Estes resultados já eram esperados, devido à conhecida incompatibilidade entre PP e HDPE. Apesar deste efeito, dependendo da aplicação visada para o material em questão, o conjunto de propriedades é aceitável. Do ponto de vista do desempenho em serviço, a resistência à tração no ponto de escoamento é mais significativa que a resistência à tração no ponto de ruptura - porque, até o limite do escoamento, o artefato resiste a esforços com pouca variação nas suas dimensões e forma, mantendo seu aspecto inicial.

$\mathrm{O}$ comportamento quanto à resistência ao impacto do PP virgem, bem como das misturas binárias $\mathrm{PP} / \mathrm{EPDM}$ e ternárias $\mathrm{PP} / \mathrm{HDPE} / \mathrm{EPDM}$ revelou, tal como esperado, que essa resistência aumentou

Tabela 2. Caracterização tecnológica de poliolefinas virgens e recicladas

\begin{tabular}{|c|c|c|c|c|c|c|}
\hline \multirow{3}{*}{$\begin{array}{c}\text { Misturas } \\
\text { PP/HDPE/EPDM } \\
(\mathbf{p} / \mathbf{p} / \mathbf{p})\end{array}$} & \multirow{3}{*}{ Densidade } & \multicolumn{5}{|c|}{ Propriedades } \\
\hline & & \multicolumn{2}{|c|}{$\begin{array}{l}\text { Resistência à tração } \\
\text { no escoamento }\end{array}$} & \multicolumn{2}{|c|}{$\begin{array}{l}\text { Resistência à tração } \\
\text { na ruptura }\end{array}$} & \multirow{2}{*}{$\begin{array}{l}\text { Resistência } \\
\text { ao impacto } \\
\qquad(\mathrm{J} / \mathbf{m})\end{array}$} \\
\hline & & $\begin{array}{l}\text { Tensão } \\
\text { (MPa) }\end{array}$ & $\begin{array}{c}\text { Alongamento } \\
(\%)\end{array}$ & $\begin{array}{l}\text { Tensão } \\
\text { (MPa) }\end{array}$ & $\begin{array}{c}\text { Alongamento } \\
(\%)\end{array}$ & \\
\hline $100 / 0 / 0$ & 0,91 & 40 & 10 & 28 & 302 & 9 \\
\hline $0 / 0 / 100$ & 0,86 & 6 & 1650 & 6 & 1666 & - \\
\hline $0 / 100 / 0$ & 0,94 & 30 & 9 & 21 & 384 & - \\
\hline $90 / 0 / 10$ & 0,90 & 31 & 8 & 25 & 378 & 17 \\
\hline $85 / 0 / 15$ & 0,90 & 25 & 8 & 22 & 401 & 21 \\
\hline $80 / 0 / 20$ & 0,90 & 24 & 7 & 23 & 477 & 33 \\
\hline $75 / 0 / 25$ & 0,89 & 21 & 8 & 25 & 499 & 37 \\
\hline $85 / 5 / 10$ & 0,91 & 28 & 6 & 23 & 52 & 37 \\
\hline $80 / 10 / 10$ & 0,91 & 29 & 6 & 24 & 14 & 25 \\
\hline $70 / 20 / 10$ & 0,91 & 28 & 6 & 27 & 9 & 26 \\
\hline Material reciclado & 0,90 & 17 & 8 & 16 & 171 & 260 \\
\hline
\end{tabular}




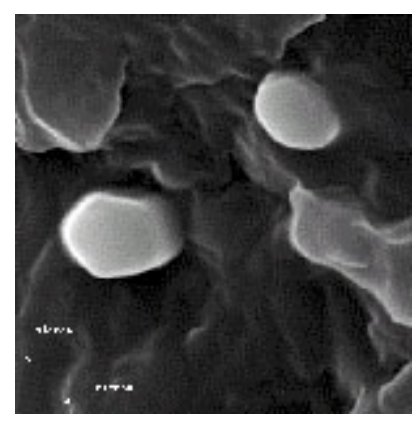

(a)

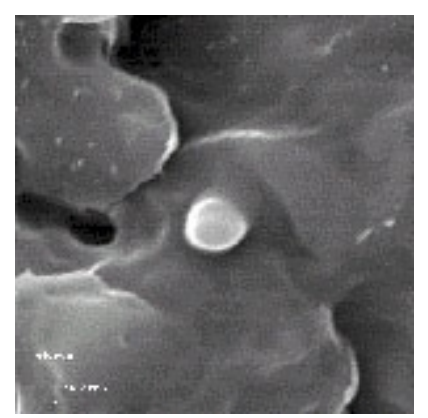

(b)

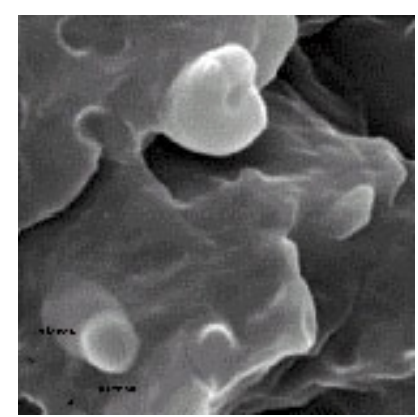

(c)

Figura 2. Fotomicrografias de misturas PP/EPDM, $20 \mathrm{kV}, 7500 \mathrm{x}$ : (a) $90 / 10$; (b) $80 / 20$; (c) $75 / 25$

progressivamente no PP com a adição de EPDM na faixa estudada (0-25\%). Nas misturas estudadas, observou-se que há um limite a partir máximo (20$25 \%$ ) do qual a adição de elastômero ao PP não se refletiu na resistência ao impacto. É interessante observar que apenas 5\% de HDPE na mistura binária PP/EPDM 85/10 foi suficiente para provocar um expressivo aumento da resistência ao impacto. Dessa forma, do ponto de vista de resistência ao impacto, que é um requisito tão importante para pára-choques de carros de passeio, a utilização de mistura ternária PP/HDPE/EPDM pode ser tão adequada quanto a mistura binária PP/EPDM. A escolha deverá então recair com base principalmente na diferença de custos oferecida pelas matérias-primas.

É importante ressaltar o exageradamente alto valor de resistência ao impacto do material reciclado - $260 \mathrm{~J} / \mathrm{m}$ - isto é, dez vezes maior que a resistência das misturas binárias e ternárias, apesar de sua menor resistência à tração. A explicação para este resultado inesperado é a presença de reticulações, decorrentes da degradação do material, associada à melhor dispersão dos domínios elastoméricos da matriz de PP, com a devida compatibilização interfacial entre esses domínios. Esta compatibilização foi favorecida no material reciclado devido ao maior esforço de cisalhamento provocado pela reciclagem, o que foi comprovado pelo torque mais baixo observado em seu processamento.

\section{Conclusões}

A irradiação ao ar aumenta a resistência mecânica do IMAWOOD ${ }^{\circledR}$. Embora tenha sido constatada uma redução no alongamento na ruptura, com a ocorrência de uma transição dúctil-frágil, pode-se afirmar que o IMAWOOD ${ }^{\circledR}$, do ponto de vista de engenharia, apresenta melhores condições para determinadas aplicações após irradiação, uma vez que o material apresenta menor fragilidade.

A reciclagem mecânica de pára-choques descartados de carros de passeio tem grande potencial para aplicação na própria indústria automobilística, em peças das quais seja exigida grande resistência ao impacto, desde que as demais propriedades do material atendam às especificações solicitadas.

\section{Agradecimentos}

Os Autores agradecem ao CNPq, CAPES, CEPG/UFRJ, FAPERJ e à Empresa Brasileira de Radiações - EMBRARAD.

\section{Referências Bibliográficas}

1. Keller, A. \& Ungar, G. - Radiation effects and crystallinity in polyethylene. Radiat. Phys. Chem., 22, 155 (1983).

2. Spadaro, G. - Effect of irradiation temperature and dose rate on the mechanical tensile behaviour of low density polyethylene. Eur. Polym. J., 29, 1247 (1993). 
3. Freitag, D. - Future aspects of engineering thermoplastics - from an industrial point of view. Prog.Polym.Sci., 19, 995 (1994).

4. Poulakis, J. G.; Varelidis, P. C. \& Papaspyrides, C. D. - Recycling of polypropylene-based composites. Adv. Polym. Techn., 16 (4) 313 (1997)

5. Miranda, V.; Lai, F. S. \& Ferdinand, R. L. - Recycling of painted modified polypropylene auto bumpers by melt filtration. ANTEC'94 (3), 2888 (1994).

6. Mapleston, P. - Auto sector's recycling keep plastics on hot. Modern Plastics International, May, 40 (1995).

7. Dao, K. C. - Rubber phase dispersion in polypropylene. Polymer, 25, 1527 (1984).

8. Mano, E. B.; Bonelli, C. M. C. \& Pacheco, E. B. A. V. - Recuperação secundária de plásticos provenientes do lixo urbano do município do Rio de Janeiro. In: Congresso Brasileiro de Polímeros, I, S.Paulo, SP. Anais... São Paulo. p.63 (1991).

9. Mano, E. B.; Dias, M. L. \& Bonelli C. M. C. The engineering materials and the recycled plastics. Latin American Applied Research, 25, 169 (1995).

10. Norma ASTM D 1708 - Tensile properties of plastics by use of microtensile specimens. American Society for Testing and Materials (1996).

11. Norma ASTM D 695(M) - Compressive properties of rigid plastics (metric). American Society for Testing and Materials (1991).

12. Martins, A. F.; Pereira, R. A. \& Mano, E. B. Recycled car bumpers impact resistance investigated by WAXS. Journ. Appl. Polym. Sci., in press (1999).

13. Mano, E. B.; Martins, A. F. \& Mendes, L. C. Thermal analysis applied to discarded car bumpers. Journ. Therm. Analysis and Calorimetry, in press (1999).

14. Norma ASTM D 256 - Determining the pendulum impact resistance of notched specimens of plastics - American Society for Testing and Materials (1993).

15. Anônimo. Technical Data on Plastics. Washington, DC: Manufacturing Chemists' Association, p.94 (1957). 